\title{
36. TRACHEOBRONCHITIS IN THE ICU
}

\section{Dan Schuller and Subramanian Paranjothi}

\section{Introduction}

Tracheobronchitis can be broadly defined as an inflammatory process of the airways between the larynx and the bronchioles. Clinically, this is a syndrome recognized by an increase in the volume and purulence of the lower respiratory tract secretions frequently associated with signs of variable airflow obstruction. In the intensive care unit (ICU), tracheobronchitis is a relatively common problem related to multiple potential insults to the airway of a critically ill host. For instance, the presence of an endotracheal tube, the frequent suctioning needed to maintain airway clearance, the process of bacterial colonization and the aspiration of contaminated secretions are only a few of the multiple triggers of an inflammatory response in the airway.

In contrast to ventilator-associated pneumonia (VAP), nosocomial tracheobronchitis is not associated with parenchymal involvement and thus, no radiographic pulmonary infiltrates. However, high quality portable chest radiographs may be difficult to obtain in the ICU, where poor patient cooperation, inconsistent technique and other obstacles may lead to inadequate studies [1]. Furthermore, common processes such as atelectasis, pulmonary edema, pleural effusions or pulmonary embolism can cause infiltrates that mimic pneumonia making this clinical distinction difficult [2].

The pathogenesis, diagnosis, preventive strategies and management of nosocomial or ventilator-associated pneumonia (VAP) are addressed extensively in various chapters of this textbook. For bacterial tracheobronchitis, the risk factors, routes and mechanisms of bacterial airway colonization are the same and will not be repeated in this section.

\section{Bacterial Tracheobronchitis}

Bacteria are among the most common causes of infectious tracheobronchitis in the ICU. Infectious tracheobronchitis is diagnosed when a patient develops fever, purulent respiratory secretions, and leukocytosis but the chest radiograph shows no new infiltrate [3]. However, when a patient lacks fever or leukocytosis the differentiation between colonization and active infection can be difficult and controversial. Furthermore the specific role that tracheobronchial colonization plays in predisposing a patient to develop a subsequent lower respiratory tract infection is unclear.

Colonization of the oropharynx has been associated with several factors including age, severity of acute and chronic illness, and hospitalization [4-6]. One study of outpatients with chronic tracheostomy concluded that patients could be managed with a low risk for developing severe respiratory tract infections, despite massive airway colonization with potentially pathogenic bacteria [7]. However, hospitalized patients with a tracheostomy or a translaryngeal endotracheal tube have both a higher frequency of tracheobronchial colonization, especially with Gram-negative enteric bacteria and $P$. aeruginosa, and also a higher risk of developing a severe lower respiratory tract infection [4, 8-11]. The upper airways and tracheo- 
bronchial tree serve a mechanical barrier function and also provide a mucociliary mechanism for removing particulate matter and microbes that have been deposited within the respiratory tract. Mucociliary clearance depends on the composition of airway secretions, an effective mucociliary escalator apparatus, and the presence of an effective cough reflex [12]. Artificial airways create a setting that is optimal for both colonization and the subsequent development of tracheobronchitis or pneumonia. Artificial airways provide direct access for bacteria to the lower respiratory tract, reduce effective cough reflex, and compromise the mucociliary escalator $[13,14]$. Furthermore, endotracheal tube insertion and suctioning may cause tracheal epithelial cell damage allowing bacterial adherence and increased mucus secretion and stagnation [15, 16]. Respiratory therapy devices including medication nebulizers, ventilator spirometer, and ventilatory circuit and condensate may play a role in harboring and transmitting bacteria [17, 18].

While colonization with Gram-positive organisms occurs, Gram-negative bacilli are much more common in ICU patients with many studies showing Pseudomonas species as the most commonly isolated organism [19-21]. While there are no useful parameters to objectively predict which of those patients who have tracheobronchial colonization will go on to develop infectious tracheobronchitis, it is clear that tracheobronchitis often develops in those patients who are colonized. In one study seven of 15 patients with a chronic tracheostomy had colonization with Pseudomonas species and all of them developed an episode of purulent tracheobronchitis [22]. George et al., found that tracheal colonization preceded ventilator-associated pneumonia in $93.5 \%$ and was a significant independent risk factor for ventilator-associated pneumonia [23].

While as a group, aerobic enteric Gramnegative bacilli account for most of the respiratory infections in ventilated patients, Staphylococcus aureus remains a very important nosocomial pathogen accounting for $20 \%$ of nosocomial respiratory infections. $S$. aureus is found in the nasopharynx in $20-40 \%$ of adults at any time with the carrier rate as high as $70 \%$ in hospitalized patients. Furthermore, patients with underlying lung disease, such as cystic fibrosis or chronic obstructive pulmonary disease, are frequently observed to have tracheobronchial colonization with $S$. aureus. The emergence of methicillin-resistant strains of Stapbylococcus aureus (MRSA) has posed a special therapeutic problem. Manifestations are not limited to nosocomial pneumonia but also have been reported to cause a fulminant tracheobronchitis [24].

Acinetobacter baumannii (formerly A. calcoaceticus var. anitratus) has emerged as an important nosocomial pathogen that is most commonly seen in the ICU setting in those patients with impaired host defenses requiring mechanical ventilation. In addition to tracheobronchitis and pneumonia, other resulting illnesses include endocarditis, peritonitis, skin and soft tissue infection, urinary tract infection, and bloodstream infection. A. baumannii infections have been linked to contaminated respiratory therapy equipment, intravascular access devices, and transmission via hands of hospital personnel [25]. Seifert et al. observed that tracheobronchitis was the presumed portal of entry for nosocomial A. baumannii bacteremia in 19 of 87 (22\%) episodes. This study also confirmed the results of other studies suggesting that the major determinants for developing A. baumannii bacteremia included treatment in an ICU, major surgery, mechanical ventilation, hyperalimentation, broad-spectrum antimicrobial therapy, and intravascular catheters [26]. Multi-drug resistance is common among these organisms limiting therapeutic options and resulting in mortality as high as $46 \%$ [27, 28].

Although Mycoplasma pneumoniae infection is best known for its ability to produce atypical pneumonia in young adults it may result in bronchitis about 30 times more often than it causes pneumonia [29]. M. pneumoniae is associated with both acute bronchiolitis and 
bronchiolitis obliterans in the infant and child as well as in the adult population. In children it is a relatively infrequent but significant cause of bronchiolitis accounting for $11 \%$ of cases of bronchiolitis due to a known agent [30]. M. pneumoniae outbreaks occur sporadically but have a predilection for the late fall and early winter [31]. Isolated bronchiolitis or bronchiolitis obliterans with organizing pneumonia (BOOP) without a patchy or lobar alveolar pneumonia is uncommon. Furthermore acute infectious bronchiolitis requiring hospitalization is relatively unusual in adults. Nonetheless $M$. pneumoniae should be considered as a cause for acute bronchitis or bronchiolitis in hospitalized patients.

The typical case of Mycoplasma infection begins insidiously with fever, nonproductive cough, headache, malaise and occasional chills. Upper respiratory symptoms of rhinitis and sore throat are present in $50 \%$ of cases. Myalgias, arthralgias, skin rash or gastrointestinal symptoms are rare; bullous myringitis and ARDS develop occasionally [32]. Rare cases of profound hypoxemia with airflow obstruction and hypercapnia have been reported presumably as a result of widespread bronchiolitis [33].

\section{Fungal Tracheobronchitis}

Fungal infections limited to the tracheobronchial tree are relatively uncommon. Clark et al., [34] reported that of a total of 207 patients, only $15(7 \%)$ had infection solely or predominantly within the airways [34-38]. The incidence of Candida infection localized to the tracheobronchial tree must be much lower as reported cases are very rare. Furthermore, some cases are poorly documented pathologically and the diagnosis of bronchial candidiasis was made solely on the basis of repeatedly positive sputum cultures and clinical improvement after treatment with antifungal agents [39, 40]. To our knowledge, there are no reported cases of Mucor spp. causing tracheobronchitis. In a case series of nine patients with fungal tracheobronchitis, the observations of Clark et al. confirmed other literature that Aspergillus was the predominant pathogen occurring alone in six of the cases and in combination with Candida spp. in one case. Candida spp. and Rbizopus spp. were each the sole responsible pathogen in one case [34].

Fungal tracheobronchitis can have two different morphological manifestations. The first consists of intraluminal growth involving more or less the entire circumference of the airway wall with only superficial mucosal invasion. Pathologically, such infection can appear as a peudomembrane in which a fibrinous exudate related to airway ulceration is prominent, or as tenacious mucus/fungus plugs more or less completely occluding the tracheobronchial tree. This is perhaps the most likely form of serious fungal infection to be missed clinically, as patients may only complain of increasing dyspnea with or without hemoptysis. Because the parenchyma is unaffected the chest roentgenograms may be normal. Thus it is important to send bronchial casts and airway debris for culture and histological analysis, especially in immunocomprised patients [34].

The second morphological form consists of one or several discrete plaques localized to a relatively small portion of the tracheobronchial tree. Although in the early stages of infection, invasion is limited to the airway mucosa, with progression of disease fungi penetrate beyond the bronchial wall into the adjacent lung parenchyma where they may result in focal pneumonia or abscess formation. Vascular invasion is not uncommon and may lead to parenchymal or pleural hemorrhage [34].

The explanation for why fungi colonize and invade the tracheobronchial tree in certain patients is unclear. However, given the underlying disorders that patients with fungal tracheobronchitis commonly have, it is clear that a deficiency in the host immune system is a common denominator among these patients. Fungal tracheobronchitis has been seen in patients with lung and bone marrow transplantation, AIDS and hematological malignancies 
[41]. Prolonged neutropenia occurring either secondary to the malignancy or chemotherapy has been shown to be a risk factor for developing invasive pulmonary aspergillosis [42]. Even in the absence of neutropenia, impaired leukocyte mobilization and function may contribute to the predisposition to fungal infection in cancer patients [43]. Corticosteroids predispose to the development of fungal invasion by inhibiting macrophage killing of spores, inhibiting phagocyte migration to the site of infection, and by suppressing antibody production, delayed hypersensitivity reaction, and wound healing [34, 44]. Broad-spectrum antibiotics change the normal flora and predispose to the development of fungal colonization. Cellular and humoral immune deficiency are additional risk factors [45].

\section{Viral Tracheobronchitis}

Many respiratory infections caused by viruses begin in the upper respiratory tract usually without producing lower respiratory symptoms. A variety of clinical syndromes including rhinitis, pharyngitis, laryngotracheitis (croup), bronchitis or tracheobronchitis, bronchiolitis and pneumonia can occur depending on the specific virus involved, the viral load, virulence, host resistance and extent of respiratory mucosal involvement [46].

The patient's age is also an important factor in the form and severity of infection; for example, rhinovirus typically causes only coryza in immunocompetent adults, whereas it is a cause of croup, bronchitis, bronchiolitis and pneumonia in children. The attack rates for respiratory sincitial virus (RSV), parainfuenza virus types 1 and 3 and adenovirus is also several folds higher in the first two years of life [46].

In the ICU, viral tracheobronchitis is usually seen in one of two situations: (a) primary viral infection usually acquired in the community, such as influenza, parainfluenza, adenovirus or RSV that is either severe or complicates underlying pulmonary disease or, (b) reactivation of a latent virus in the nosocomial setting, such as herpes simplex virus (HSV) or cytomegalovirus (CMV). Either situation can further be complicated by bacterial co-infection or superinfection [47].

\section{INFLUENZA VIRUS}

Influenza virus infection usually involves only the upper respiratory tract, including trachea and major bronchi; however in a small percentage of patients, particularly the chronically ill or the elderly, it may be responsible for severe pneumonia. It can occur in pandemics, epidemics or sporadically. Almost all severe epidemics and all pandemics are caused by type $\mathrm{A}$ influenza. Typical winter outbreaks occur every year in temperate climates with a less predictable seasonal variation in tropical areas. Transmission occurs from person to person with an incubation period of 24-48 hours and is highly contagious. Viral shedding and infectivity can persist for as long as two weeks in children, but probably less in adults [48]. Antibody formation to specific strains by either immunization or infection confers immunity for 1-2 years. Serologic studies have found a higher incidence of antibodies to influenza $\mathrm{A}$ and $\mathrm{B}$ in health care workers than controls [49]. The risk of developing a complicated course is increased in older individuals, those with a significant history of tobacco smoking, comorbidities and pregnancy [50-52].

The clinical manifestations are variable and depend on the virulence of the influenza virus strain, the underlying condition and response of the host. The flu-like syndrome with rapid onset of dry cough, myalgias, headache, chills and fever without major pulmonary complaints affects predominantly young adults. Another syndrome seen in influenza is the bronchitis/ tracheobronchitis with no radiographic abnormality but with more respiratory distress and sometimes associated with hemoptysis, exacerbation of underlying asthma or COPD. In more severe cases, spread of the virus to the pulmonary parenchyma causes clinical worsening within 
12-36 hours with worsening dyspnea, tachypnea, cyanosis and hypoxemia $[53,54]$. Finally, it is well recognized that superinfection with Staphylococcus aureus, Streptococcus pneumoniae, Hemophilus influenzae or other bacterias can occur after influenza [55].

The diagnosis can be confirmed by culturing the virus from respiratory secretions. More rapid diagnostic methods available consist of direct immunofluorescence assay (DFA), polymerase chain reaction (PCR) or the new rapid assays that detect activity of influenza neuraminidase or viral nucleoproteins [56].

Influenza vaccination is the mainstay of protection against the disease. The older drugs available for the prevention and treatment of influenza are amantadine and rimantadine. However, their use is limited by by lack of activity against Influenza B, rapid emergence of resistance and, especially with amantidine, central nervous sytem toxicity. New agents available for the treatment of influenza $\mathrm{A}$ and $\mathrm{B}$ include the neuraminidase inhibitors zanamivir that is delivered by inhalation and oseltamivir phosphate available orally [57].

\section{PARAINFLUENZA VIRUS}

In adults, parainfluenza is responsible for pharyngitis and coryza; in infants and children it is the predominant cause of severe croup. Immunocompromised individuals are at increased risk for more severe presentations. Parainfluenza type 1 and 2 occur predominantly in the autumn and early winter. Parainfluenza type 3 occurs in the spring and is an important cause of bronchiolitis or pneumonia in infants and children. Lower respiratory tract involvement in adults is uncommon.

The clinical manifestations in adults are acute pharyngitis and tonsillitis. When complicated by pneumonia it is indistinguishable from other viral or Mycoplasma infection. The radiographic findings are nonspecific. The organism can be isolated by culture of sputum or nasopharyngeal secretions. Immunofluorescent antibody is useful for rapid identification.
There are currently no available antiviral agents with proven effectiveness against parainfluenza virus. Ribavirin is active against the virus in vitro, but there have been no randomized controlled trials in humans.

\section{RHINOVIRUS}

Rhinovirus causes approximately $40-50 \%$ of common cold cases. Clinically significant lower respiratory tract infection in adults is uncommon but includes acute bronchitis, bronchiolitis and pneumonia. Perhaps more important is the indirect effect that such an infection may have in patients with asthma, COPD or other medically debilitating states. Rhinovirus infection has been associated with exacerbation of COPD and respiratory failure [58].

\section{ADENOVIRUS}

Adenovirus can cause pharyngitis, pharyngoconjuntivitis, laryngotracheo-bronchitis, bronchiolitis, pneumonia or a non-specific acute respiratory syndrome; there is also some evidence that it may cause some cases of bronchiectasis, bronchiolitis obliterans and hyperlucent lung syndrome [59]. Infections can occur sporadically or in epidemics. Localized nosocomial outbreaks have also been reported.

The adenoviruses are the most common cause of the ARDS, a poorly defined condition consisting of fever, pharyngitis, cough, hoarseness, chest pain, and conjunctivitis. Chills and myalgias may be present. In some cases, tracheobronchitis is prominent and may be indistinguishable from the classic whooping cough caused by Bordetella pertussis. When pneumonia occurs it is typically mild and associated with upper respiratory symptoms. However, a few fatal cases have been seen with autopsy studies revealing extensive areas of hemorrhagic consolidation with alternating areas of atelectasis and hyperinflation. The airways frequently show marked airway congestion with mucopurulent or hemorrhagic material. In most cases the infection is self-limited and the treatment is supportive. 


\section{RESPIRATORY SYNCYTIAL VIRUS}

Respiratory syncytial virus (RSV) is particularly important as a cause of bronchiolitis in infants and small children. Infection occurs predominantly during the winter months and early spring. Transmission occurs by airborne droplets or hand-to-hand contact. The disease is highly contagious and there is evidence that health care workers are at increased risk for infection [49].

In adults, the disease is usually mild and limited to the upper respiratory tract. However, in the elderly, chronically ill, immunocompromised or hospitalized patient, lower tract involvement can occur [60]. Rarely, RSV can cause acute pneumonia with rapid progression to ARDS [61].

The clinical manifestations reflect the extent of airway involvement. Nasal congestion and discharge usually precede the cough and wheezing by 2-3 days, but may occur simultaneously. In contrast to Influenza infection, RSV is associated with relatively little risk of bacterial superinfection. The radiological findings usually reflect a disparity between the severity of respiratory symptoms and a paucity of abnormalities. However, bronchial wall thickening, peribronchial infiltrates or lobular consolidation may occur.

RSV can be cultured from nasopharyngeal or lower respiratory secretions. In adults and transplant patients, bronchoalveolar lavage is more sensitive than throat swabs [62]. The shell-vial culture has been shown to be a rapid and sensitive method. PCR and immune based assays including antigen detection by immunofluorescence or enzyme-linked immunosorbent assay (ELISA) are available for rapid diagnosis.

In addition to supportive care, severe cases of RSV infection have been treated with aerosolized ribavirin $(6 \mathrm{~g}$ reconstituted in $300 \mathrm{ml}$ of sterile water to a final concentration of $20 \mathrm{mg} / \mathrm{ml}$ and administered 12 to 18 hours per day for 3-7 days); although no clinical trials have been conducted in this patient population. There is no data regarding the use of oral ribavirin.

\section{HERPES SIMPLEX VIRUS}

Herpes simplex virus (HSV) was first recognized as a pulmonary pathogen by Morgan and Finland almost a half century ago [63]. Stern et al. [64] first focused attention on the possibility of herpetic involvement of the trachea and its transmission via contaminated secretions from an infected patient to a health care worker, causing herpetic whitlow. Later reports of herpetic respiratory infections have included patients with underlying diseases [65, 66], extensive burns [67], underlying malignancy, chemotherapy and radiation therapy [68], and critically ill patients with ARDS [69-72].

Herpetic tracheobronchitis has also been reported in immunocompetent patients without history of chronic lung disease [73-75], in patients after extracorporeal circulation for cardiac surgery [76], and following general surgery [77-79].

Despite the apparent increasing prevalence of pulmonary HSV, the relationship between respiratory $\mathrm{HSV}$ isolation, pulmonary function, and clinical outcome is not well documented. HSV type 1 in lower respiratory secretions has been associated with unresolved acute bronchospasm [73], prolonged requirement for mechanical ventilation [73-79], tracheal stenosis, and increased mortality [79, 80]. However, asymptomatic viral shedding of HSV also occurs in approximately one per cent to five per cent of asymptomatic normal individuals [81].

The concept of airway injury leading to viral reactivation has been reported previously in autopsy series $[67,82,83]$ and in patients who have undergone surgery $[73,79]$. One reason for this susceptibility of "traumatized" epithelium to viral colonization and potential subsequent inflammation may be that HSV typically infects squamous epithelium [84]. Thus, factors that promote squamous metaplasia, such as trauma, smoking, radiation therapy, or chemotherapy, may predispose the patient to lower respiratory tract infection with HSV [84].

At the present time, to our knowledge, there are no defined criteria for the diagnosis or treat- 
ment of herpetic tracheobronchitis. Simple isolation of HSV from respiratory secretions is clearly insufficient to make this diagnosis, since HSV can be asymptomatically shed in up to five per cent of asymptomatic adults, and the incidence of reactivation or shedding is increased in patients with airway injury. Thus, one usually makes the diagnosis based on a combination of the viral cultures, direct bronchoscopic examination of the endobronchial tree, cytological examination of tracheal or bronchial washings, and the clinical status of the patient.

The most frequent clinical manifestations exhibited by the patients are fever, productive cough and dyspnea. Frequency of these symptoms does not differ between the immunocompromised and immunocompetent patients. However, immunocompetent patients have significantly more bronchospasm. These data imply that the pathogenicity of HSV in the respiratory tract may vary depending on underlying immune status and the host response [85].

In addition, the role of primary infection versus reactivation in the spectrum of clinical manifestations of tracheobronchitis is unclear. One could speculate that respiratory HSV isolation in the immunocompromised patients most often represents "asymptomatic" shedding, perhaps due to reactivation, with less airway inflammation and, consequently, less bronchial hyperactivity. For unclear reasons, the clinical manifestations of HSV infection are more severe in the immunocompetent population; this may represent a more exuberant local immune response.

Whether to treat critically ill patients with lower respiratory tract HSV isolation with acyclovir is uncertain and controversial at this time. At the present time, it seems reasonable to treat with intravenous acyclovir $(8 \mathrm{mg} / \mathrm{Kg}$ every 8 hours for 10 days) those patients with HSV isolation from lower respiratory secretions if, in addition, they have a clinical syndrome or bronchoscopic findings consistent with tracheobronchitis. However, future prospective, randomized trials that assess the impact of treatment on the outcome of both the apparently asymptomatic HSV "carrier" and those patients with clinical HSV tracheobronchitis are needed to clarify this issue. In addition, given the risk of horizontal transmission of HSV-1 to health care workers, full compliance with infection control measures, including use of gloves and goggles when there is any potential for contact with secretions, is recommended [86].

\section{CYTOMEGALOVIRUS}

Cytomegalovirus (CMV) has been cultured with increasing frequency from patients on prolonged mechanical ventilatory support [87]. Similarly to the case of HSV, the clinical spectrum of CMV can range from asymptomatic viral shedding to a severe disease with profound immunosupression, pneumonitis and multi-organ dysfunction syndrome. In contrast to HSV where the predominant involvement occurs in the airways, CMV typically involves the pulmonary parenchyma, leading to interstitial pneumonitis or diffuse alveolar damage. CMV infection has been shown to potentiate effects of bacterial infections, possibly through impairment of neutrophil migration or macrophage activation, and has been implicated in promoting bacterial translocation [79]. Cardiac surgery patients with CMV infection complicating mediastinitis have been shown to have persistence of local infection, prolonged hospitalization and increased mortality [88]. Trauma patients with HSV or CMV reactivation have also been shown to have increased ventilator dependence and increased superimposed bacterial pneumonias [89].

As with other organisms, several techniques are available to detect CMV. The virus can be isolated from various body fluids (e.g. blood, urine, respiratory secretions) and buffy coat culture may be useful. Use of shell-vial technique yields results within $24-36$ hours. Additional, even more sensitive techniques include immunoglobulin-labeled immunomagnetic beads, fluorescent antibody staining, in situ hybridization, and PCR have also been utilized to identify CMV antigens. However, a major 
limitation of these tests is that it does not differentiate infection from disease. Thus, it is sometimes necessary to obtain tissue in order to assess the cytopathic effects.

The drugs effective against CMV are ganciclovir and foscarnet. However, the decision to treat an individual patient has to balance the risk of the patient, the evidence of disease and the potential toxicity associated with treatment.

\section{Summary}

Tracheobronchitis is increasingly recognized as a common syndrome in the ICU. The most common etiology is infection caused by bacterial, fungal, or viral pathogens. The clinical manifestations are variable and not specific for individual pathogens. The clinical distinction between incidental airway colonization and significant infection is difficult but carries important therapeutic and prognostic implications. A high index of suspicion with the appropriate diagnostic and treatment intervention can lead to an improved outcome.

\section{Acknowledgment}

We are indebted to Margie Galkowski for preparing the manuscript.

\section{References}

1. Siegal MD, Tocino I. Chest radiology in the intensive care unit. Clin Pulmonary Med 6:347, 1999.

2. Santos E, Talusan A, Brandestetter RD. Radiographic mimics of pneumonia in the critical care unit. Crit Care Clin 14:91, 1998.

3. Niederman MS, Craven DE, Fein AM, et al. Respiratory infection complication long-term tracheostomy: the implication of persistent Gram-negative tracheobronchial colonization. Chest 85:39, 1984.

4. Johanson WG, Pierce AK, Sanford JP, et al. Nosocomial respiratory infections with gramnegative bacilli. Ann Intern Med 77:701, 1972.

5. Örtqvest $\AA$, Hammers-Berggren S, Kalin M. Respiratory tract colonization and incidence of secondary infection during hospital treatment of community-acquired pneumonia. Eur J Clin Microbiol Infect Dis 9:725, 1990.

6. Salata RA, Ellner JJ. Bacterial colonizaton of the tracheobronchial tree. Clin Chest Med 91:623, 1988.

7. Harlid R, Andersson G, Frostell CG, et al. Respiratory tract colonization and infection in patients with chronic tracheostomy: a one-year study in patients living at home. Am J Respir Crit Care Med 154:124, 1996.

8. Rogers RM, Weiler C, Ruppenthal B. Impact of the respiratory intensive care unit on survival of patients with acute respiratory failure. Chest 62:94, 1972.

9. Cross AS, Roup B. Role of respiratory assistance devices in endemic nosocomial pneumonia. Am J Med 70:681, 1981.

10. Niederman MS, Ferranti RD, Zeigler A, et al. Respiratory infection complicating long-term tracheostomy. Chest 85:39, 1984.

11. Bartlett JT, Faling LJ, Willey S. Quantitative tracheal bacteriological and cytologic studies in patients with long-term tracheostomies. Chest 74:635, 1978.

12. Levine SA, Niederman MS. The impact of tracheal intubation on host defenses and risks for nosocomial pneumonia. Clin Chest Med 12:523, 1991.

13. Gal TJ. How does tracheal intubation alter respiratory mechanics? Probl Anesth 2:191, 1988.

14. Klainer AS, Turndorf H, Wu WH, et al. Surface alterations due to endotracheal intubation. Am J Med 58:674, 1975.

15. Ramphal R, Guay P. Pseudomonas aeruginosa adhesions for tracheobronchial mucin. Infect Immun 55:600, 1987.

16. Ramphal R, Pyle M. Adherence of mucoid and nonmucoid Pseudomonas aeruginosa to acidinjured tracheal epithelium. Infect Immun 41:345, 1983.

17. Craven DE, Goularte TA, Make BJ. Contaminated condensate in mechanical ventilator circuits: a risk factor for nosocomial pneumonia. Am Rev Respir Dis 129:625, 1984.

18. Craven DE, Lichtenberg DA, Goularte TA, et al. Contaminated medication nebulizers in mechanical ventilator circuits: source of bacterial aerosols. Am J Med 77:834, 1984.

19. Schwartz SN, Dowling JN, Benkovic C, et al. Sources of gram-negative bacilli colonizing the trachea of intubated patients. J Infect Dis 138: 227, 1978. 
20. Niederman MS, Mantovani R, Schoch $\mathrm{P}$, et al. Patterns and routes of tracheobronchial colonization in mechanically ventilated patients: the role of nutritional status in colonization of the lower airway by Pseudomonas species. Chest 95:155, 1989.

21. Johanson WG Jr, Pierce AK, Sanford JP, et al. Nosocomial respiratory infections with gramnegative bacilli: the significance of colonization of the respiratory tract. Ann Intern Med 77:701, 1972.

22. Niederman MS, Ferranti RD, Ziegler A, et al. Respiratory infection complicating long-term tracheostomy: The implication of persistent gram-negative tracheobronchial colonization. Chest 85:39, 1984.

23. George DL, Falk PS, Wunderink RG, et al. Epidemiology of ventilator-acquired pneumonia based on protected bronchoscopic sampling. Am J Respir Crit Care Med 158:1839, 1998.

24. Namba Y, Mihara N, Tanaka M. Fulminant tracheobronchitis caused by methicillin-resistant Staphylococcus aureus (MRSA) (Japanese). Nihon Kyobu Shikkan Gakkai Zasshi. Jap J Thoracic Dis 35:969, 1997.

25. Cefai C, Richads J, Gould FK, et al. An outbreak of Acinetobacter respiratory tract infection resulting from incomplete disinfection of ventilatory equipment. J Hosp Infect 15:177, 1990.

26. Seifert H, Strate A, Pulverer G. Nosocomial bacteremia due to Acinetobacter baumanniii: Clinical features, epidemiology, and predictors of mortality. Medicine 74:340, 1995.

27. Seifert H, Baginski R, Schulze A, et al. Antimicrobial susceptibility of Acinetobacter species. Antimicrob Agents Chemother 37:750, 1993.

28. Chen YC, Chang SC, Hsieh WC, et al. Acinetobacter calcoaceticus bacteremia: analysis of 48 cases. J Formosan Med Assoc 90:958, 1991.

29. Leigh MW, Clyde WA. Chlamydial and mycoplasmal pneumonias. Semin Respir Infect 2:152, 1987.

30. Glezen WP, Loda FA, Clyde WA, et al. Epidemiologic patterns of acute lower respiratory disease of children in a pediatric practice. $J$ Pediatr 78:397, 1971.

31. Rose RM, Pinkston P, O'Donnell C, et al. Viral infection of the lower respiratory tract. Clin Chest Med 8:405, 1987.

32. Fischman RA, Marschall KE, Kislak JW, et al. Adult respiratory distress syndrome caused by Mycoplasma pneumonia. Chest 74:471, 1978.
33. Zack MB, Kazemi H. Carbon dioxide retention in Mycoplasma pneumonia. Am Rev Respir Dis 107:1052, 1973.

34. Clarke A, Skelton J, Fraser RS. Fungal tracheobronchitis: report of 9 cases and review of the literature. Medicine 70:1, 1991.

35. Meyer RD, Young LS, Armstrong D, et al. Aspergillosis complicating neoplastic disease. Am J Med 54:6, 1973.

36. Orr DP, Myerowitz RL, Dubois PJ. Pathoradiologic correlation of invasive pulmonary aspergillosis in the compromised host. Cancer 41:2028, 1978.

37. Young RC, Bennett JE, Vogel CL, et al. Aspergillosis. The spectrum of the disease of 98 patients. Medicine 49:149, 1970.

38. Dubois PJ, Myerowitz RL, Allen CM. Pathoradiologic correlation of pulmonary candidiasis in immunosuppressed patients. Cancer 40:1026, 1977.

39. Chakravarty SC. Bronchopulmonary candidiasis: Clinical aspects. Dis Chest 51:608, 1967.

40. Wengrower D, Or R, Segal E, Kleinman Y. Bronchopulmonary candidiasis exacerbating asthma. Case report and a review of the literature. Respiration 42:209, 1985.

41. Kramer MR, Denning DW, Marshall SE, et al. Ulcerative tracheobronchitis after lung transplantation: a new form of invasive aspergillosis. Am Rev Respir Dis 144:552, 1991.

42. Gerson SL, Talbot GH, Hurwitz S, et al. Prolonged granulocytopenia: the major risk factor for invasive pulmonary aspergillosis in patients with acute leukemia. Ann Intern Med 100:345, 1984.

43. Lehrer RI, Cline MJ. Leukocyte candidacidal activity and resistance to systemic candidiasis in patients with cancer. Cancer 27:1211, 1971.

44. Dale DC, Petersdorf RG. Corticosteroids and infectious diseases. Med Clin North Am 57:1277, 1973.

45. Bodey GP. Candidiasis in cancer patients. Am J Med 77(Suppl 4D):13, 1984.

46. Denny FW Jr. The clinical impact of human respiratory virus infections. Am J Respir Crit Care Med 152:S4, 1995.

47. Ellenbogen C, Graybill JL, Silva J, et al. Bacterial pneumonia complicating viral pneumonia. Am J Med 56:169, 1974.

48. Frank AL, Taber LH, Wells CR, et al. Patterns of shedding of myxoviruses and paramyxoviruses in children. J Infect Dis 144:433, 1981.

49. Davies KJ, Herbert AM, Westmoreland D, et al. Seroepidemiological study of respiratory virus 
infections among dental surgeons. Br Dent $\mathrm{J}$ 176:262, 1994.

50. Kark JD, Lebiush M, Rannon L. Cigarette smoking as a risk factor for epidemic $A\left(\mathrm{H}_{1} \mathrm{~N}_{1}\right)$ influenza in young men. $\mathrm{N}$ Engl J Med 307: 1042, 1982.

51. Mullooly JP, Barker WH, Nolan TF Jr. Risk of acute respiratory disease among pregnant women during influenza A epidemics. Public Health Rep 101:205, 1986.

52. Conway SP, Simmonds EJ, Littlewood JM. Acute severe deterioration in cystic fibrosis associated with influenza A virus infection. Thorax 47:112, 1992.

53. O'Brien TG, Sweeney DF. Interstitial viral pneumonitis complicated by severe respiratory failure: successful management using intensive dehydration and steroids. Chest 63:314, 1973.

54. Roberts GBS. Fulminating influenza. Lancet 2:944, 1957.

55. Winther B, Brofeldt S, Gronborg H, et al. Study of bacteria in the nasal cavity and nasopharynx during naturally acquired common cold. Acta Otolaryngol 98:315, 1984.

56. The Medical Letter, Inc. Rapid diagnostic tests for influenza 41:121, 1999.

57. Calfee DP, Hayden FG. New approaches to influenza chemotherapy. Neuraminidase inhibitors. Drugs 56:537, 1998.

58. Smith CB, Kanner RE, Golden CA, et al. Effect of viral infection on pulmonary function in patients with chronic obstructive pulmonary diseases. J Infect Dis 141:271, 1980.

59. Bateman ED, Hayashi S, Kuwano K, et al. Latent adenoviral infection in follicular bronchiectasis. Am J Respir Crit Care Med 151:170, 1995.

60. Morales F, Calder MA, Inglis JM, et al. A study of respiratory infections in the elderly to assess the role of respiratory syncytial virus. J Infect 7:236, 1983.

61. Zaroukian MH, Kashyap GH, Wentworth BB. Case report: respiratory syncytial virus infection: a case of respiratory distress syndrome and pneumonia in adults. Am J Med Sci 295:218, 1988.

62. Englund JA, Piedra PA, Jewell A, Patel K, Baxter BB, Whimbey E. Rapid diagnosis of respiratory syncytial virus infection in immunocompromised adults. J Clin Microbiol 34:1649, 1996.

63. Morgan HR, Finland M. Isolation of herpes virus from a case of atypical pneumonia and erythema multiforme exudativum: with studies of four additional cases. Am J Med Sci 217:92, 1949.
64. Stern H, Elek SD, Millar DM, Anderson HF. Herpetic whitlow: a form of cross-infection in hospitals. Lancet 2:871, 1959.

65. Lheureux P, Verhest A, Vincent JL, Liénard C, Levivier M, Kahn RJ. Herpes virus infection, an unusual source of adult respiratory distress syndrome. Aur J Respir Dis 67:72, 1985.

66. Benjamin DR. Herpes simplex tracheobronchitis and pneumonitis. Pediatr Pathol 9:773, 1989.

67. Nash G, Foley FD. Herpetic infection of the middle and lower respiratory tract. Am J Clin Pathol 54:857, 1970.

68. Ramsey PG, Fife KH, Hackman RC, Mayers JD, Corey L. Herpes simplex virus pneumonia: clinical, virologic, and pathologic features in 20 patients. Ann Intern Med 97:813, 1982.

69. Frable WJ, Frable MA, Seney FD Jr. Virus infections of the respiratory tract: cytopathologic and clinical analysis. Acta Cytol 21:32, 1977.

70. Tuxen DV, Wilson JW, Cade JF. Prevention of lower respiratory herpes simplex virus infection with acyclovir in patients with the adult respiratory distress syndrome. Am Rev Respir Dis 136:402, 1987.

71. Tuxen DV, Cade JF, McDonald MI, Buchanan MR, Clark RJ, Pain MC. Herpes simplex virus from the lower respiratory tract in adult respiratory distress syndrome. Am Rev Respir Dis 126:416, 1982.

72. Prellner T, Flamholc L, Haidl S, Lindholm K, Widell A. Herpes simplex virus - the most frequently isolated pathogen in the lungs of patients with severe respiratory distress. Scand J Infect Dis 24:283, 1992.

73. Sherry MK, Klainer AS, Wolff M, Gerhard H. Herpetic tracheobronchitis. Ann Intern Med 109:229, 1988.

74. Legge RH, Thompson AB, Linder J, Woods GL, Robbins RA, Moulton AL, et al. Acyclovirresponsive herpetic tracheobronchitis. Am J Med 85:516, 1988.

75. Chakraborty A, Forker A, Reese H, Casey J. Tracheobronchitis and pneumonia due to herpes simplex virus (HSV) infection. Nebr Med J 73:347, 1988.

76. Vaxelaire JF, Brunet F, Armaganidis A, Pochard F, Giraud T, Lanore JJ, et al. The role of herpes simplex virus in respiratory complications after cardiac surgery (abstract). Am Rev Respir Dis 143:A474, 1991.

77. Porteous C, Bradley JA, Hamilton DN, Ledingham IM, Clements GB, Robinson CG. Herpes simplex virus reactivation in surgical patients. Crit Care Med 12:626, 1984. 
78. Avery RK, Longworth DL. Viral pulmonary infections in thoracic and cardiovascular surgery. Sem Thoracic Cardiovasc Surg 7:88, 1995.

79. Cook CH, Yenchar JK, Kraner TO, Davis EA, Ferguson RM. Occult herpes family viruses may increase mortality in critically ill surgical patients. Am J Surg 176:357, 1988.

80. St. John RC, Pacht ER. Tracheal stenosis and failure to wean from mechanical ventilation due to herpetic tracheitis. Chest 98:1520, 1990.

81. Corey L, Spear PG. Infections with herpes simplex viruses. N Engl J Med 314:749, 1986.

82. Nash G. Necrotizing tracheobronchitis and bronchopneumonia consistent with herpetic infection. Hum Pathol 3:283, 1972.

83. Graham BS, Snell JD Jr. Herpes simplex virus infection of the adult lower respiratory tract. Medicine 62:384, 1983.

84. Herout V, Vortel V, Vondrackova A. Herpes simplex involvement of the lower respiratory tract. Am J Clin Pathol 46:411, 1966.

85. Schuller D, Spessert C, Fraser JV, Goodenberger
DM. Herpes simplex virus from respiratory tract secretions: epidemiology, clinical characteristics, and outcome in immunocompromised and nonimmunocompromised hosts. Am J Med 94:29, 1993.

86. Perl TM, Haugen TH, Pfaller MA, Hollis R, Lakeman AD, Whitley RJ, et al. Transmission of herpes simplex virus type 1 infection in an intensive care unit. Ann Intern Med 117:584, 1992.

87. Papazian L, Fraisse L, et al. Cytomegalovirus. An unexpected cause of ventilator-associated pneumonia. Anesthesiology 84:280, 1996.

88. Domart Y, Trouillet JL, Fagan JY, Chastre J, Brun-Vezinet F, Gilbert C. Incidence and morbidity of cytomegaloviral infection in patients with mediastinitis following cardiac surgery. Chest 97:18, 1990.

89. Cushing $\mathrm{D}$, et al. Herpes simplex virus and cytomegalovirus excretion associated with increased ventilator days in trauma patients. J Trauma 35:161, 1993. 